Research Paper:

\title{
Endoscopic Surgical Management of Intracranial Symptomatic Arachnoid Cyst
}

\author{
Forhad Hossain Chowdhury ${ }^{1^{*}}$ (D), Mohammod Raziul Haque ${ }^{1}$ (D) Noman Khaled Chowdhury ${ }^{1}$, Shamsul Islam Khan ${ }^{1}$, Noor Mohammod $^{2}$
}

\author{
1. Department of Neurosurgery, Dhaka Medical College Hospital, Dhaka, Bangladesh \\ 2. Department of Radiology, Comilla Medical College, Comilla, Bangladesh
}

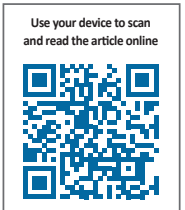

Cftation: Hossain Chowdhury F, Raziul Haque M, Khaled Chowdhury N, Islam Khan Sh, Mohammod N. Endoscopic Surgical Management of Intracranial Symptomatic Arachnoid Cyst. Iran J Neurosurg. 2018; 4(2):61-74. http://dx.doi.org/10.32598/irjns.4.2.61

doi: : http://dx.doi.org/10.32598/irjns.4.2.61

\section{(i) (\$)}

Funding: See Page 71

Article info:

Received: 02 December 2017

Accepted: 25 February 2018

Available Online: 01 April 2018

Keywords:

Intracranial, Symptomatic, Arachnoid cyst, Endoscopic surgical management, Cysto-ventriculostomy, Cystocisternostomy, Endoscopy

\section{ABSTRACT}

Background and Aim: Intracranial Arachnoid Cysts (IAC) are suitable choices for endoscopic procedure to avoid craniotomy or shunt placement. Our main objective is to study the outcome of endoscopic procedure in IAC treatment.

Methods and Materials/Patients: In this descriptive and retrospective study, we reported our experience of 27 symptomatic patients with IAC who underwent endoscopic surgery at National Institute of Neurosciences Hospital and Dhaka Medical College Hospital, Dhaka, Bangladesh from January 2009 to December 2016. The recorded data of patients' management including operations, outcomes, and follow up were studied retrospectively. The diagnosis was confirmed by neuroimaging, surgery and histopathological examination. The patients were postoperatively followed up on regular basis.

Results: The size of the IAC decreased (significant to minimal) in all cases. Even if the size reduction were minimal, patients' symptoms would improve significantly. No IAC increased in size after endoscopic procedure. There was no recurrence of symptoms in the follow up period. There was no postoperative mortality or major morbidity related to the surgery.

Conclusion: Based on our results, most of symptomatic IAC cases can be managed by endoscopic procedure which seems to be a safe and effective method.

\section{* Corresponding Author:}




\section{Highlights}

- Intracranial Arachnoid Cysts (IACs) are suitable candidates for endoscopic procedure

- The size of the IAC decreased (significant to minimal) in all studied cases after endoscopic intervention.

- Even if size reduction wereminimal, the patients' symptoms would improve significantly.

- There was no recurrence of symptoms in the follow up period.

- There was no postoperative mortality or major morbidity.

- Most of the symptomatic IAC cases can safely and effectively be managed by endoscopic procedure

\section{Plain Language Summary}

Intracranial Arachnoid Cysts (IACS) are CSF containing cysts encased in arachnoid membrane that may produce clinical symptom/s. Symptomatic ones require surgical treatment. IACs are suitable choices for endoscopic procedure to avoid open craniotomy or shunt placement. Here, the outcome of endoscopic procedure in IAC treatment was studied retrospectively. We reported our experience of 27 symptomatic patients with IAC who underwent endoscopic surgery at National Institute of Neurosciences Hospital and Dhaka Medical College Hospital, Dhaka, Bangladesh from January 2009 to December 2016. The recorded data of the patients' management, including operations, outcomes, and follow up were studied retrospectively. The diagnosis was confirmed by neuroimaging, surgery and histopathological examination. The patients were postoperatively followed up on regular basis. Size of the IACs decreased (significant to minimal) in all cases. Even if size reduction were minimal, patients' symptoms would improve significantly. There was no recurrence of symptoms or increase in the size of the cyst in the follow up period. There was no postoperative mortality or major morbidity related to the surgery. Based on our results, most symptomatic IAC cases can safely and effectively be managed by endoscopic procedure.

\section{Introduction}

ntracranial cysts are among the most common conditions presented to neurosurgeons. They can be congenital or acquired $[1,2]$. The most common intracranial cyst is arachnoid cyst [3]. Intracranial Arachnoid

Cysts (IACS) are benign cystic lesions filled with Cerebrospinal Fluid (CSF), enclosed in arachnoid-like membrane [4]. Most arachnoid cysts remain asymptomatic throughout the life [5]. The prevalence of arachnoid cyst in children is $2.6 \%$ and in adults $1.4 \%$ [6-8].

The clinical manifestations depend on the location and size of the cyst [4]. They are incidental findings on Computed Tomography (CT) or Magnetic Resonance Imaging (MRI) performed for other reasons such as trauma [5]. In symptomatic patients, many treatments are available [4]. In the present era of minimally-invasive neurosurgery, an endoscopic procedure for an IAC makes the treatment easier and safer [3]. This study aims to investigate the outcome of endoscopic treatment in
IAC. Here, we also studied the other observational data related to the surgical management of IAC.

\section{Methods and Materials/Patients}

In this descriptive retrospective study, we reported our experience of 27 symptomatic patients of IAC who underwent endoscopic surgery from January 2009 to June 2016 in the department of Neurosurgery, National Institute of Neurosciences Hospital and Dhaka Medical College Hospital, Dhaka, Bangladesh. As patients with IAC can be symptomatic or asymptomatic, asymptomatic ones were informed of their situation, assured and followed up.

Symptomatic patients were evaluated to be certain that the symptoms were due to the cyst both clinically and radiologically. Thus, the patients were evaluated and investigated accordingly prior to surgery. In all patients, we collected data regarding age, sex, symptoms at presentation, indication for imaging, location of IAC, treatment modality used, and their outcomes taken retrospectively from pa- 


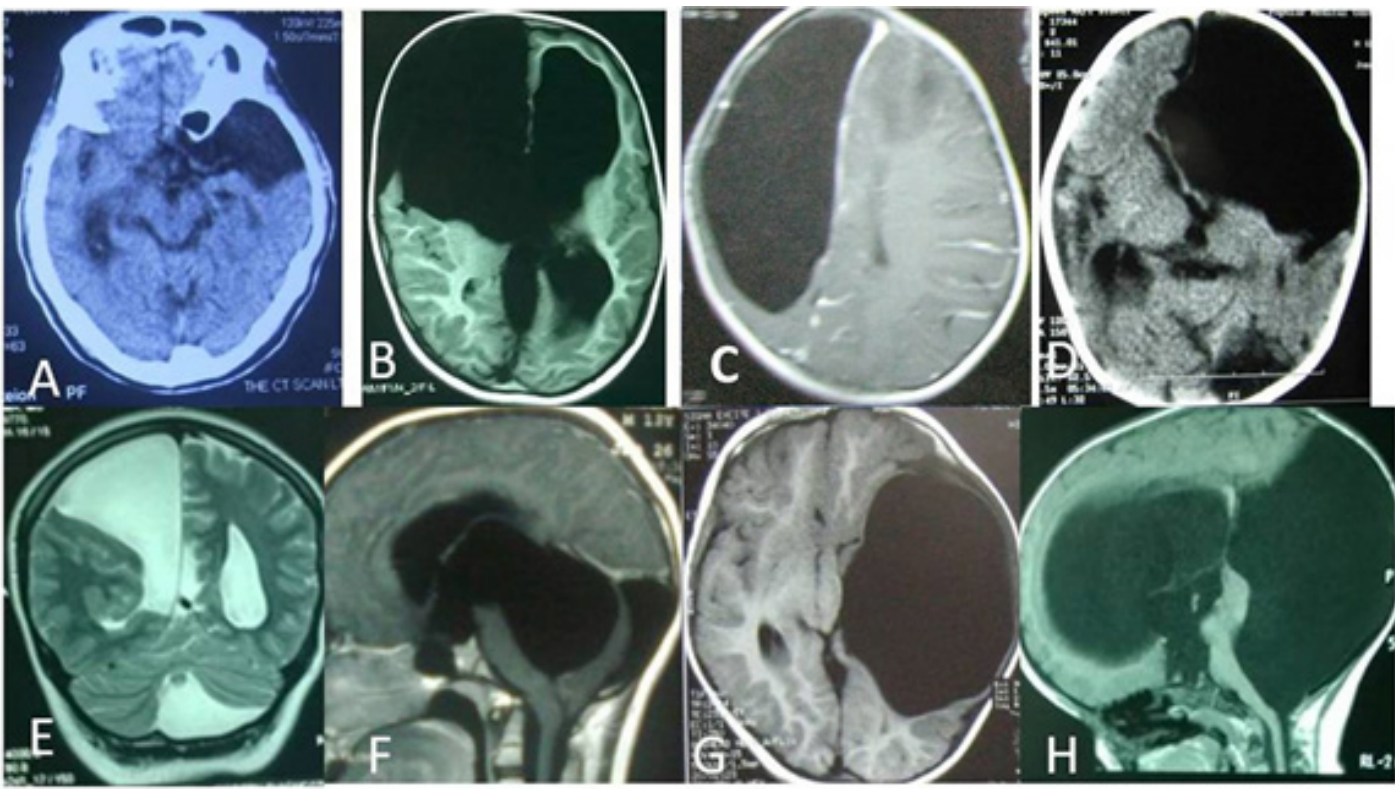

Figure 1. CT and MRI images of different types of IAC

A: Anterior temporal IAC; B: Frontal both extra- and intra-dural IAC; C: Frontal IAC; D: Large frontotemporal IAC; E: Parasagittal (parafalcine) IAC; F: Supracerebellar (pineal) IAC; G: Temporoparietal IAC; and H: Posterior fossa IAC with extension to supratentorial compartment.

tients' files. In all patients, the diagnosis was confirmed by neuroimaging, during surgery and histopathological examination. The patients were postoperatively followed up clinically and radiologically (CT scan or MRI of brain) on regular basis and their recorded follow up data were studied. The patients, who were lost from follow up within 6 months after operation, were excluded from this study.

\section{Results}

A total of 27 patients with IAC underwent surgery. The patients' follow up period lasted between 9 to 89 months (average 18.5 months). Fourteen patients were males and 13 were females, the mean age at the time of surgery was 14.7 years (range: 4 months to 5 years). Eight cases were below 12 months old. Eighteen cases were under 15 years old. Of 27 IACs, 20 were in the supratentorial region, 4 in the infratentorial and 3 were in both supra- and infra-tentorial regions (These IAC were extended from posterior fossa to the third and lateral ventricles through pineal region; tentorium cerebelli seemed to be intact but elevated). All IAC cases were intradural except one where the cyst was partially extradural (Figures 1, 2, and 3). Twelve patients had Hy-

Table 1. Clinical features of IAC cases before and after operation $(n=27)$

\begin{tabular}{ccc}
\hline Clinical Features of IAC & No. (\%) & \\
\cline { 2 - 3 } Headache & Before Operation & After Operation \\
\hline Hydrocephalus & $14(51.8)$ & $11(40.7)$ \\
\hline Head asymmetry (Figure 2) & $12(44.4)$ & $12(44.4)$ \\
\hline Epilepsy & 4 & $0(0)$ \\
Gait disturbance & 1 & $1(100)$ \\
Limb weakness & 5 & $4(80)$ \\
\hline Visual disturbances (Figure 6) & 1 & $1(100)$ \\
\hline
\end{tabular}


Table 2. Age, sex, site of IAC, endoscopic procedure and important notes of the study subjects

\begin{tabular}{|c|c|c|c|}
\hline Age/Sex & Site & Endoscopic Surgical Procedure & Important Notes \\
\hline $9 \mathrm{y} / \mathrm{M}$ & Left temporal & CC (basal cistern) & -- \\
\hline 12 Mon/M & $\begin{array}{l}\text { Right } \\
\text { frontoparieto-temporal }\end{array}$ & CV (frontal horn) & $\begin{array}{l}\text { Simultaneous left frontal hemor- } \\
\text { rhage }\end{array}$ \\
\hline $9 \mathrm{y} / \mathrm{M}$ & $\begin{array}{l}\text { Right frontal with } \\
\text { extradural cyst }\end{array}$ & CV (Frontal horn) & $\begin{array}{l}\text { Symptoms were gone but very mini- } \\
\text { mal radiological reduction of IAC }\end{array}$ \\
\hline $4 \mathrm{Mon} / \mathrm{F}$ & Posterior fossa & $\begin{array}{c}\text { ETV (at } 4 \text { months); } \\
\text { CV (Through posterior parietal trans-trigonal, } 3 \\
\text { years old) }\end{array}$ & Cyst grew with age of the patient \\
\hline $50 \mathrm{y} / \mathrm{F}$ & Right posterior parietal & CV (lateral ventricle) & $\begin{array}{l}\text { Preoperative -total blindness; Visual } \\
\text { recovery near to normal) after opera- } \\
\text { tion }\end{array}$ \\
\hline $45 \mathrm{y} / \mathrm{F}$ & Left parieto-occipital & $\begin{array}{l}\text { First: Burr hole evacuation of CSDH, later: CV } \\
\text { (lateral ventricle) }\end{array}$ & $\begin{array}{c}\text { There was simultaneous Right fron- } \\
\text { toparietal CSDH }\end{array}$ \\
\hline $14 \mathrm{y} / \mathrm{M}$ & Right frontotemporal & CV (frontal horn) & -- \\
\hline 7 Mon/M & Right frontoparietal & CV (frontal horn) & -- \\
\hline $6 \mathrm{Mon} / \mathrm{M}$ & Left frontoparietal & CV (lateral ventricle) & Bilateral occipital encephalomalacia \\
\hline $10 \mathrm{y} / \mathrm{F}$ & Right occipital & $\begin{array}{l}\text { Through occipital burr hole-CV (occipital horn)+ } \\
\text { through Kocher's point burr hole-ETV }\end{array}$ & HCP resolved \\
\hline $47 \mathrm{y} / \mathrm{F}$ & Third ventricular cyst & CV+ETV (double fenestration) & $\begin{array}{l}\text { HCP resolved. There was cirrhosis } \\
\text { of liver. }\end{array}$ \\
\hline $06 \mathrm{Mon} / \mathrm{F}$ & Right frontal & CV (frontal horn) & $\begin{array}{l}\text { Unilateral HCP (mono lateral ven- } \\
\text { tricular HCP) }\end{array}$ \\
\hline $31 \mathrm{y} / \mathrm{F}$ & $\begin{array}{l}\text { Right paramedian } \\
\text { (median longitudinal } \\
\text { fissure), parietal }\end{array}$ & $\begin{array}{l}\text { Endoscopic microsurgical transcallosal CV (lateral } \\
\text { ventricle) }\end{array}$ & $\begin{array}{l}\text { Preoperative hemiplegia-recovered } \\
\text { post operatively }\end{array}$ \\
\hline $13 \mathrm{y} / \mathrm{M}$ & $\begin{array}{l}\text { Supracerebellar-pinealo- } \\
\text { 3rd ventricular }\end{array}$ & $\mathrm{ETV}+\mathrm{CV}$ (trans third ventricular) & -- \\
\hline $12 \mathrm{Mon} / \mathrm{F}$ & $\begin{array}{l}\text { Whole post fossa } \\
\quad+\text { occipital }\end{array}$ & $\begin{array}{l}\text { ETV- through Kocher's point burr hole + CV (lat- } \\
\text { eral ventricle)-through a more anterior burr hole }\end{array}$ & Preoperative $\mathrm{HCP}$ resolved \\
\hline $7 \mathrm{Mon} / \mathrm{F}$ & Pineal huge HCP & ETV + CV (Third ventricle) & HCP. Two frontal burr holes \\
\hline $3 \mathrm{y} / \mathrm{M}$ & Right frontoparietal & CC (basal cistern) & -- \\
\hline $7 \mathrm{y} / \mathrm{F}$ & Third ventricular & CV+ETV(double fenestration) & -- \\
\hline $17 \mathrm{y} / \mathrm{F}$ & $\begin{array}{l}\text { Right sided } \\
\text { cerebellopontine angle }\end{array}$ & $\begin{array}{l}\text { Endoscopic microsurgical -CC (Prepontine cis- } \\
\text { tern, double fenestration) }\end{array}$ & -- \\
\hline $9 \mathrm{y} / \mathrm{M}$ & $\begin{array}{l}\text { Suprasellar } \\
\text { arachnoid cyst }\end{array}$ & $\begin{array}{c}\text { CV+ETV (Double fenestration)-at } 9 \text { years old. Re- } \\
\text { ETV at } 16 \text { years of age }\end{array}$ & $\begin{array}{l}\text { Stoma block seven years after opera- } \\
\text { tion (re-appearance of HCP) }\end{array}$ \\
\hline $29 \mathrm{y} / \mathrm{F}$ & Left parietal & $\begin{array}{l}\text { Transparietal lobule- Endoscopic microsurgical } \\
\text { (with Neuronavigation)CV (lateral ventricle) }\end{array}$ & -- \\
\hline $23 \mathrm{y} / \mathrm{M}$ & Right temporal & $\begin{array}{l}\text { Endoscopic microsurgical transtemporal } \\
\text { CV(temporal horn)+CC (basal cistern) }\end{array}$ & Preoperative seizure was gone \\
\hline $55 \mathrm{y} / \mathrm{F}$ & $\begin{array}{l}\text { Right } \\
\text { frontoparietotemporal }\end{array}$ & $\begin{array}{l}\text { Endoscopic microsurgical frontal transcortical } \\
\text {-CV (frontal horn) }\end{array}$ & -- \\
\hline $17 \mathrm{y} / \mathrm{M}$ & Suprasellar cyst & ETV+CV (Double fenestration) & -- \\
\hline $3 / \mathrm{M}$ & Suprasellar IAC & ETV+CV (Double fenestration) & -- \\
\hline $1 / \mathrm{M}$ & Left frontal IAC & CV (frontal horn) & -- \\
\hline 18 Mon/M & Right frontoparietal & CV (frontal horn) & -- \\
\hline
\end{tabular}

Abbreviations: y: year; M: Male; F: Female; IAC: Intracranial Arachnoid Cyst; CV: Cysto-Ventriculostomy; CC: Cysto-Cisternostomy; ETV: Endoscopic Third Ventriculostomy; HCP: Hydrocephalus; CSDH: Chronic Subdural Hematoma 


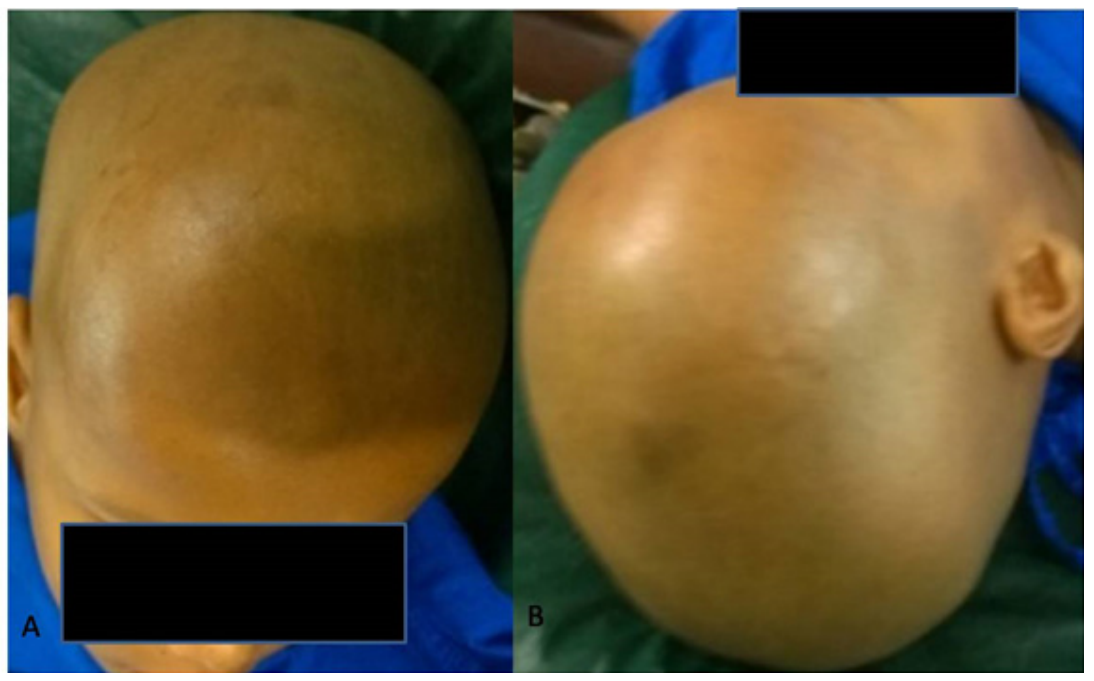

Figure 2. Asymmetry in the frontal region between right and left side due to underlying arachnoid cyst
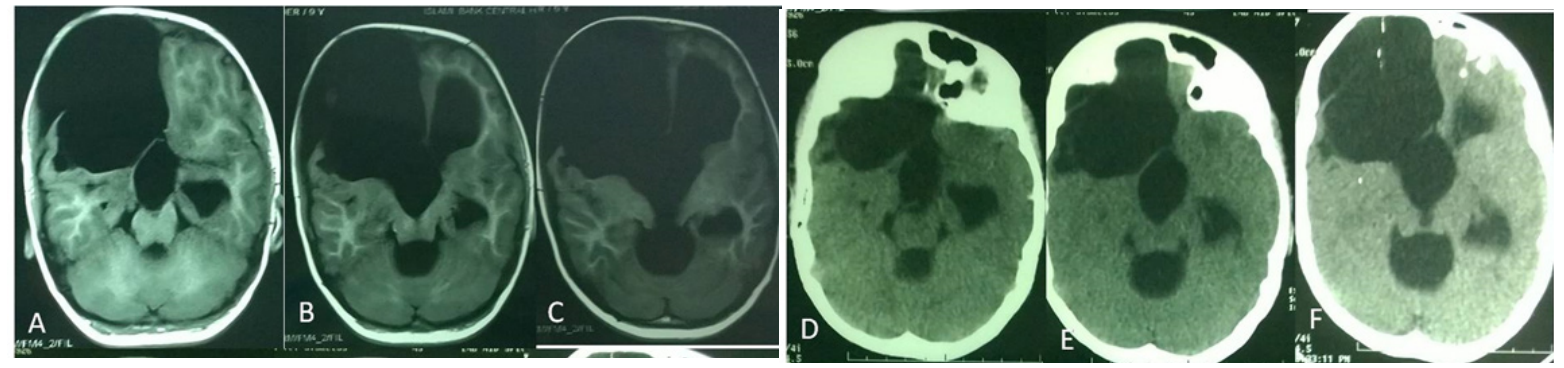

Figure 3. Preoperative and postoperative neuro-images of the patient

A, B, and C: Preoperative MRI of brain axial sections in T1W showing both extra- and intra-dural right frontal IAC (Figure 2); C, D, and F: Post CV CT scan of head axial images showing very minimum reduction of size of IAC (though symptoms were gone).

drocephalus (HCP) (including one mono-ventricular $\mathrm{HCP}$ ) (Figure 3, 4, and 5). Clinical features are shown in Table 1. Two patients had chronic headache with sudden exaggeration where imaging showed Intracerebral Hemorrhage $(\mathrm{ICH})$ in one case (Figure 6) and chronic subdural hematoma in another case.
Imaging findings

Only brain CT scan had been done in 6 cases and only brain MRI in 14 cases whereas both $\mathrm{CT}$ and MRI had been done in 7 cases. On neuro-imaging, mass effect of IAC was seen in all the cases in the form of sulcal effacement, neighboring cortex depression, ventricular

Table 3. Mortality, major morbidity, recurrence/reoperation with follow up

\begin{tabular}{ccccc}
\hline Cases $(\mathbf{n = 2 7 )}$ & No. & $\%$ & Follow Up: 89-09 Mon; Average: 18.5 Mon \\
\cline { 5 - 5 } & & 00 & 00 & One patient died 4 years after operation due to cirrhosis of liver \\
\hline Perioperative mortality & 00 & 00 & Due to stoma obstruction (after 7 years) \\
\hline $\begin{array}{c}\text { Postoperative new neurodeficit } \\
\text { Recurrence of symptom/s }\end{array}$ & 01 & 3.7 & Re-ETV \\
\hline Re-operation & 01 & 3.7 &
\end{tabular}




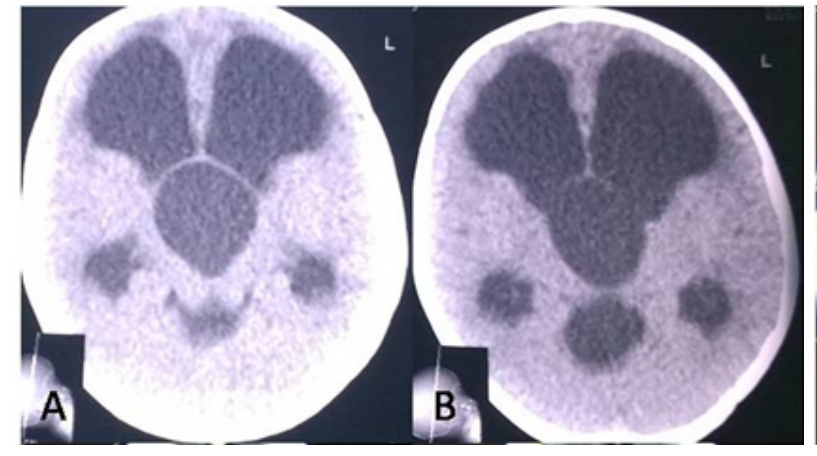

Figure 4. Pre- and post-operative CT scan of head

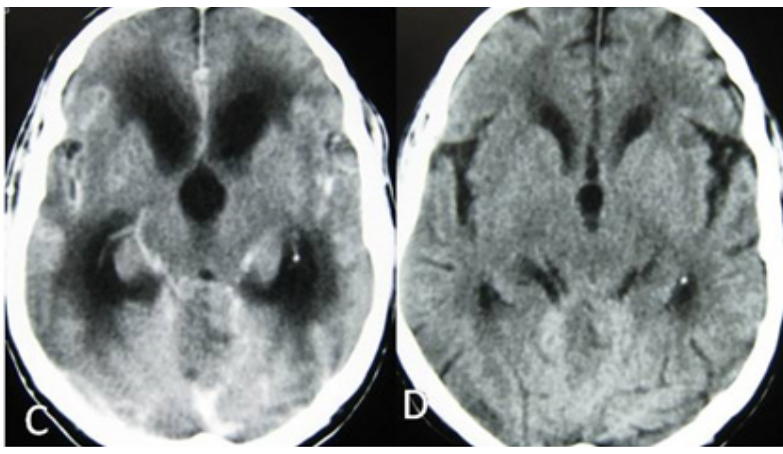

Ts

A, B: Preoperative CT scan of brain at the age of 9 years showing suprasellar/third ventricular IAC; C: CT scan of brain at the age of 16 showing development of triventriculomegaly due to stoma block; D: Postoperative CT scan of head after ETV.

effacement or enlargement, and midline shift. Hypoplasia of the adjacent brain parenchyma was also found in most of the cases, especially temporal lobe hypoplasia in temporal/sylvian IAC. Thirteen were in the right side, 5 in the left side, and 9 in the midline.

Age, sex, site, operative procedures and important notes are shown in Table 2 (Figures 1-11). Mortality, major morbidity, and recurrence/reoperation with follow up are presented in Table 3. Flexible endoscope was used in three cases whereas rigid endoscopy was used in 21 cases. Flexible endoscope was replaced by rigid endoscope in later part of surgery in 3 cases. It seemed that working with rigid endoscope was faster let alone its better illumination and vision. Pure endoscopy was used in 23 cases while endoscopic microsurgical (rigid endoscope+microsurgical instruments) techniques were used in 4 cases. In one case, neuronavigation assistance was taken during microsurgical transcortical cysto-ventriculostomy.

Cysto-Cisternostomy (CC) was done only in three cases, Cysto-Ventriculostomy (CV) (Figures 6, 7, and 8) was done in 13 cases, CC+CV was done in 1 case and CV+ETV (endo-

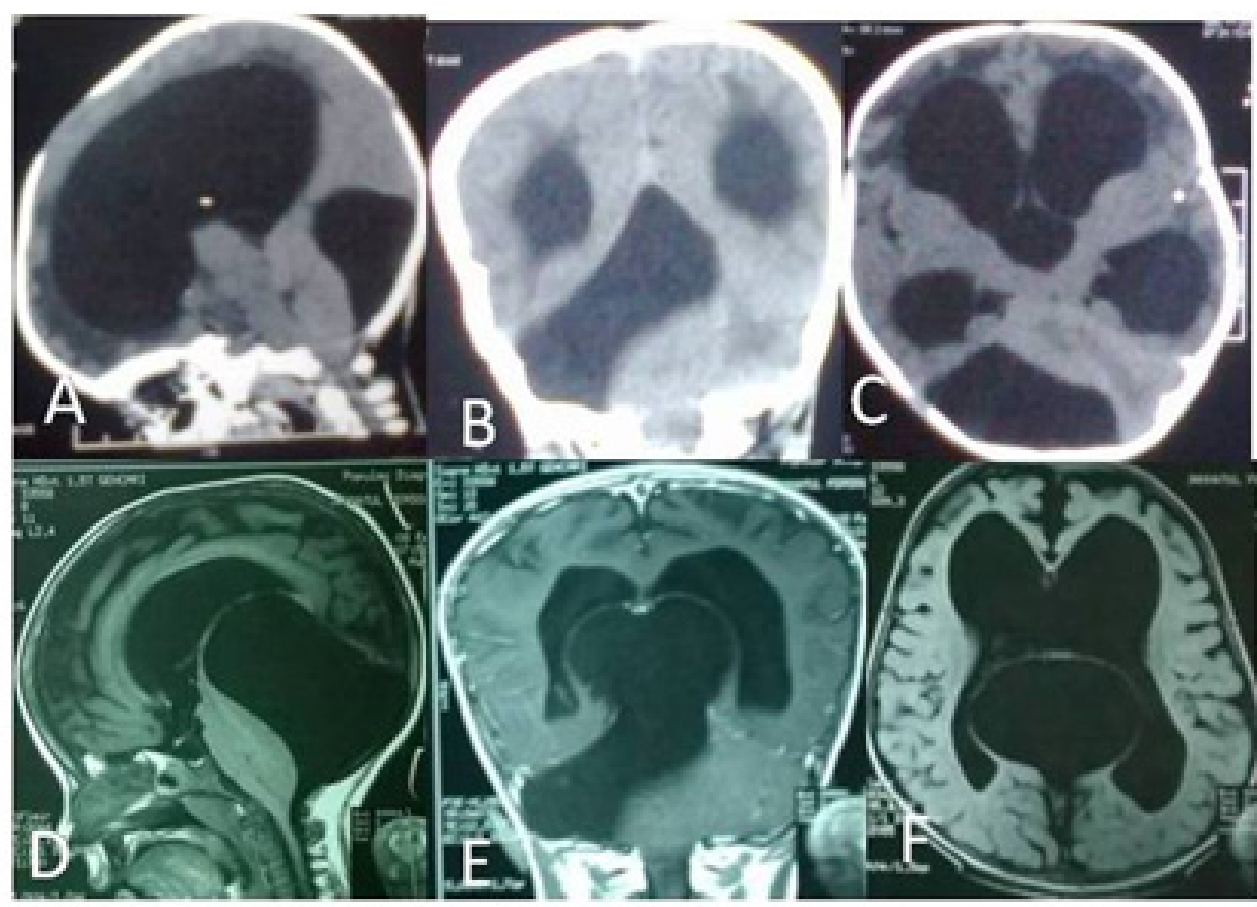

Figure 5. CT scan of head

A: Sagittal; B: Coronal; C: Axial image before ETV at the age of three months, showing posterior fossa IAC with triventriculomegaly. Post ETV MRI of brain at the age of three, D: T1W sagittal; E: Contrast coronal; and F: T1W axial images showing growth of IAC and extended into lateral ventricle (for which translateral ventricular CV needed). 


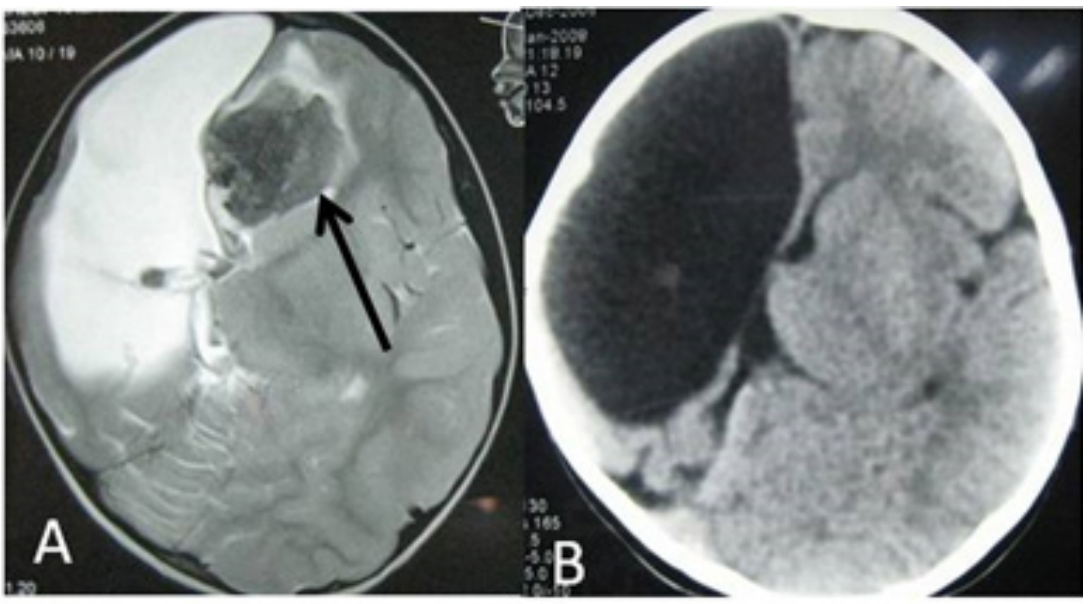

Figure 6. Pre- and post-operative neuro-images

A: MRI of brain T2W axial image showing right sided IAC with left frontal intracerebral hemorrhage; B: Postoperative CT scan of head showing cyst as like that of preoperative image (though symptoms were gone).

scopic third ventriculostomy) (Figure 5), including 'double fenestration' (Figure 9) was done in 10 cases, where HCP was present. Hydrocephalus in CP angle IAC resolved after CC. Mono-ventricular HCP was resolved with the treatment of IAC i.e. cysto-ventriculostomy. In the case of IAC with Intracerebral Hemorrhage (ICH), only CV was done and ICH was resolved spontaneously (Figure 6). Chronic subdural hematoma was treated earlier before CV in the case of IAC with chronic subdural hematoma.

Single burr hole was done in 20 cases, two burr holes were done in 3 cases and small craniotomy $(2 \times 2 \mathrm{~cm})$ done in four cases of endoscopic microsurgical procedure (Figures 10 and 11). In one case, ETV was done at the age of 4 months and cysto-ventriculostomy was done at the age of 3 years where cyst enlarged and insinuated into lateral ventricle (trigone and body) (Figure 5). Thus, posterior parietal transcortical transventricular CV was done. This patient also had corpus callosal agenesis.

Preoperative bleeding occurred in three cases that was controlled with irrigation and endoscope tip pressure/ inflated Fogarty catheter balloon. In one case, partial injury of fornix occurred near foramina of Monro with-

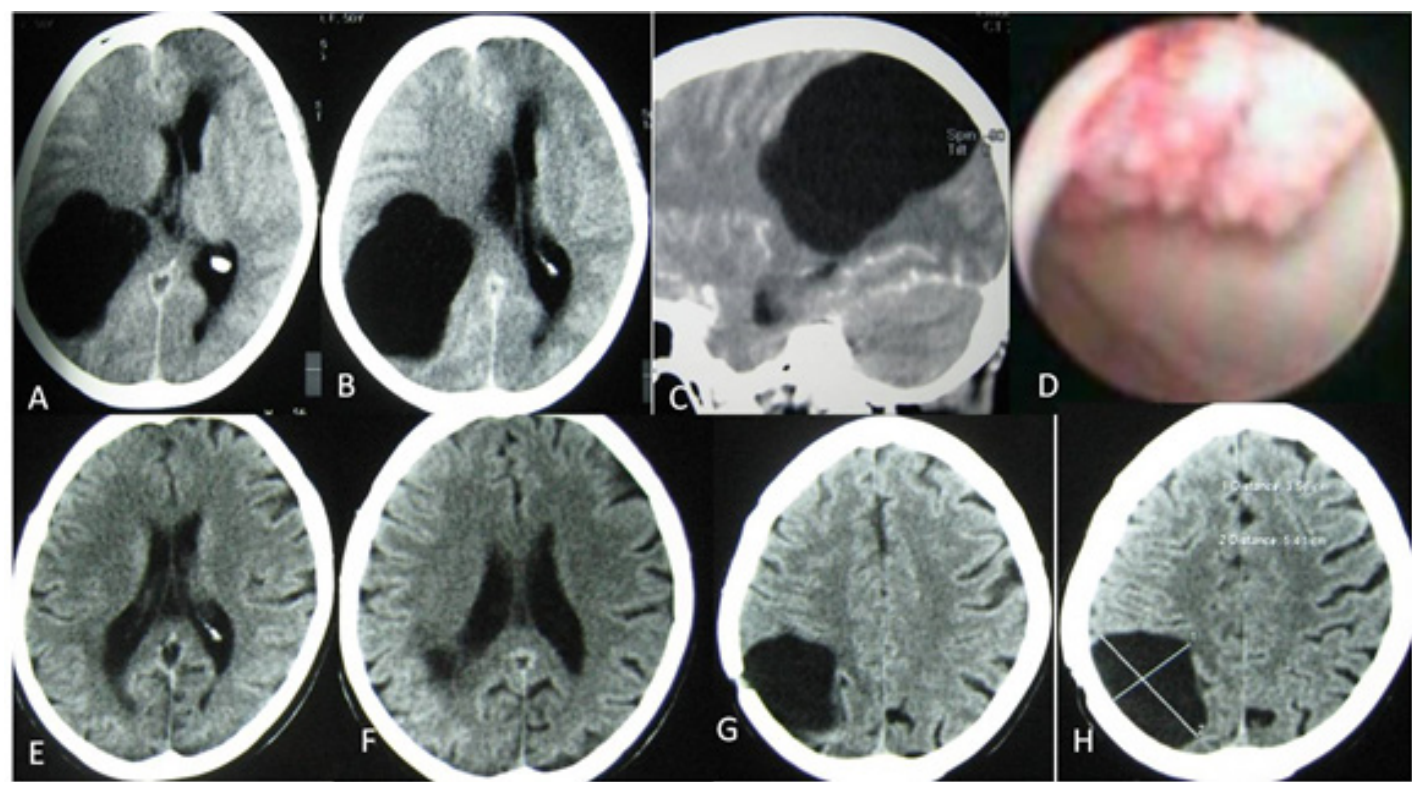

Figure 7. Preoperative CT scan of head

A and B: Axial section; C: Sagittal section showing right parieto-occipital IAC with mass effect; D: Preoperative picture of ventricular choroid plexus after $\mathrm{CV} ; \mathrm{E}, \mathrm{F}, \mathrm{G}$, and $\mathrm{H}$ : Postoperative $\mathrm{CT}$ scan of head axial section after $\mathrm{CV}$ showing reduced size IAC without any mass effect. 


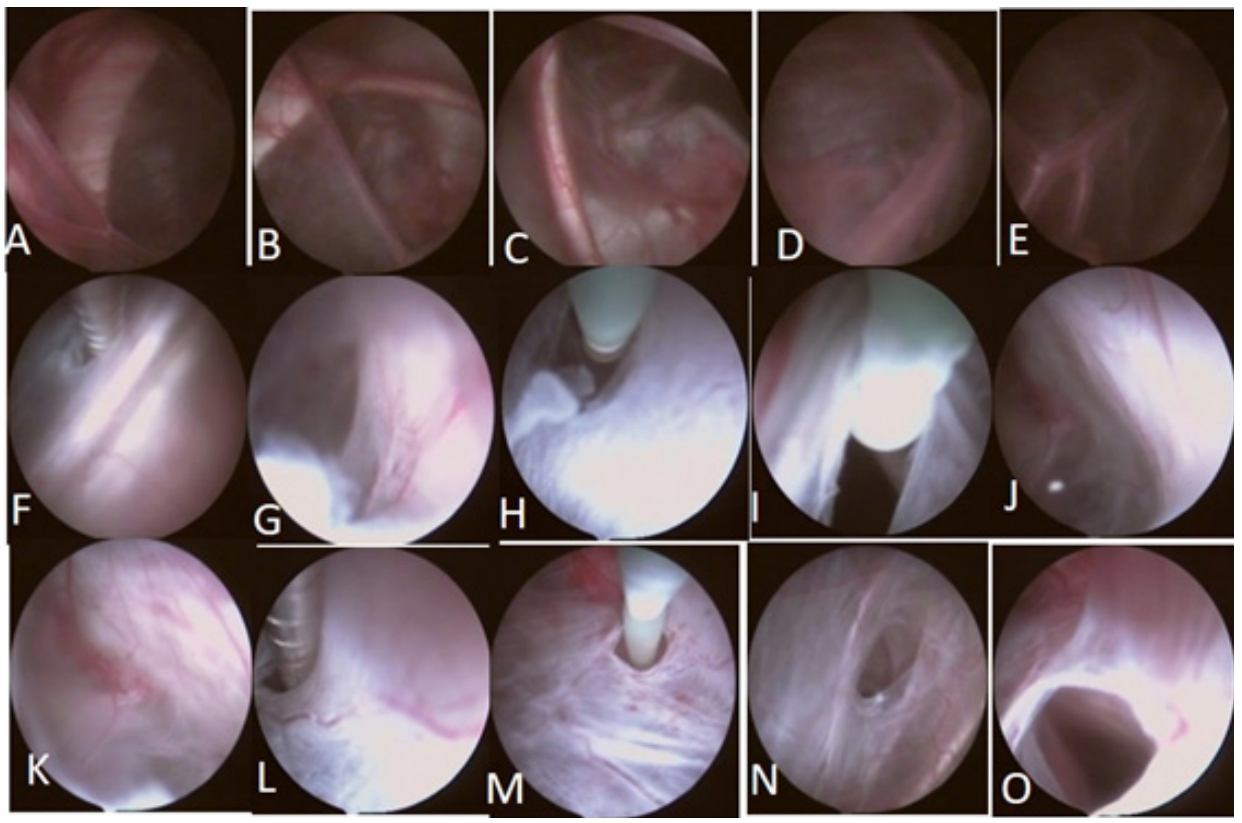

Figure 8. Preoperative sequential picture of different stages of endoscopic 'double fenestration' of a suprasellar/third ventricular IAC

A, B, C, D, E, F, G, H, and I: First wall fenestration; J, K, L, M, N, and O: Second wall fenestration.

out any postoperative complication. Histopathology confirmed the diagnosis of 'arachnoid cyst', in all cases. Most of the patients were discharged within three days after operation (range 2 to 7 days). Preoperative hospital stays were between 1 to 14 days.

Early postoperative convulsions occurred in two cases which were managed with injectable antiepileptic. Post- operative fever $\left(37.5^{\circ}-38.3^{\circ} \mathrm{C}\right)$ occurred in 4 cases. Minor wound infection (i.e. stitch infection) occurred in two cases.

A patient with preoperative hemiplegia (recovered almost completely six weeks after operation (Figures 9, 10, and 11).

In all cases of IAC, size of the cyst decreased (significant to minimal, seen in follow up images in comparison

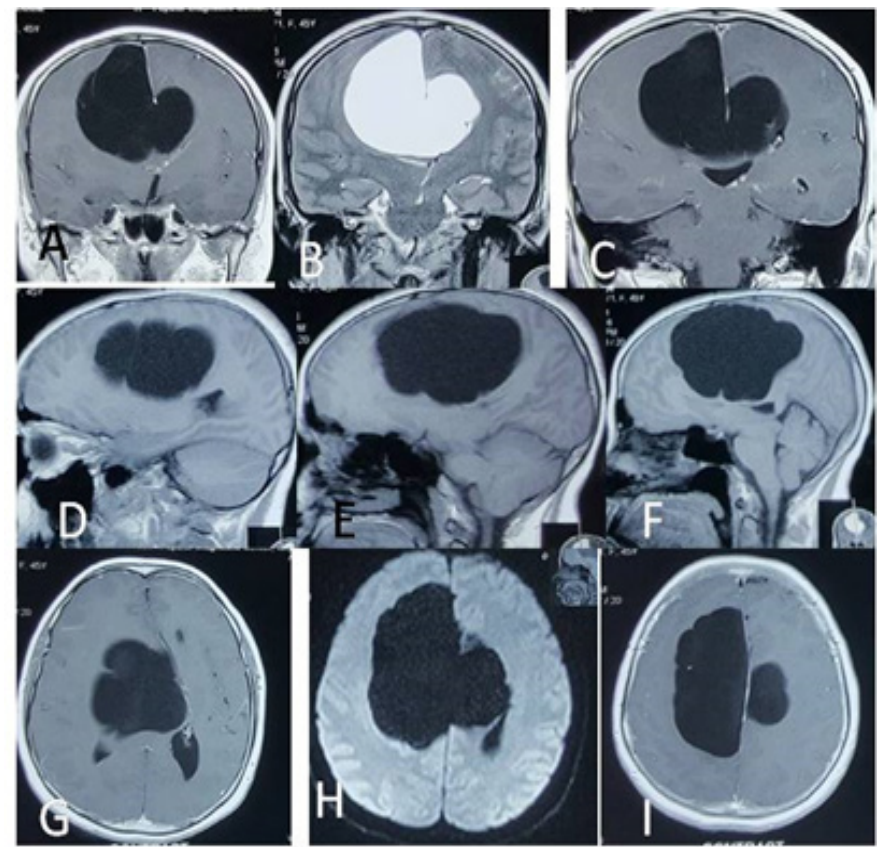

Figure 9. Preoperative MRI images of brain of frontoparietal interhemispheric IAC with mass effects

A and C: Contrast coronal; B: T2W coronal images. D, E, and F: T1W sagittal images; G and I: Contrast axial and H: DW image. 


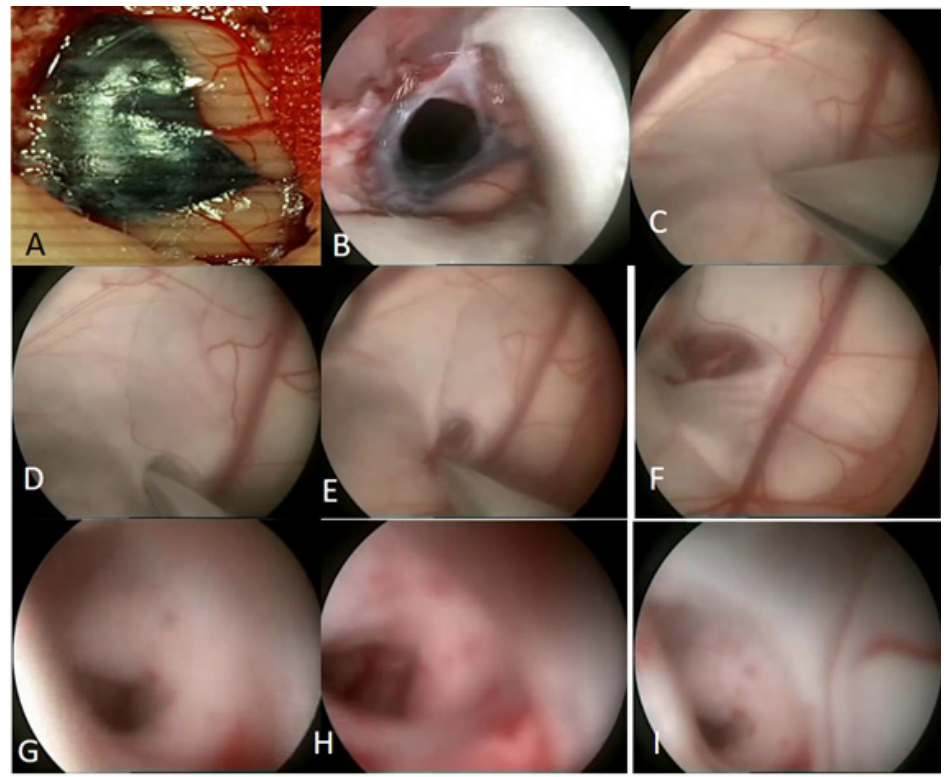

Figure 10. Preoperative sequential images in the way of endoscopic microsurgical transcallosal CV of the interhemispheric IAC (Figure 11)

A: After durotomy; B: Just before entering into cyst; C: Just before callosotomy; D, E, F, G, H, and I: Different steps in the way of transcallosal CV.

to the preoperative images). First follow-up image was done before hospital discharge and second follow-up image was taken 8-12 weeks after operation. Even if size reduction were minimal, patient's symptoms would improved significantly within 1 day to 12 weeks (average: 2 weeks). No IAC increased in size after endoscopic proce- dures. Preoperatively, two patients had visual problems; one who was preoperatively completely blind regained vision near to normal within 3 months after the operation (Figure 7) and the other one remained unchanged.

There was no recurrence of symptoms in the follow up period (average 18.5 months). There was no postopera-

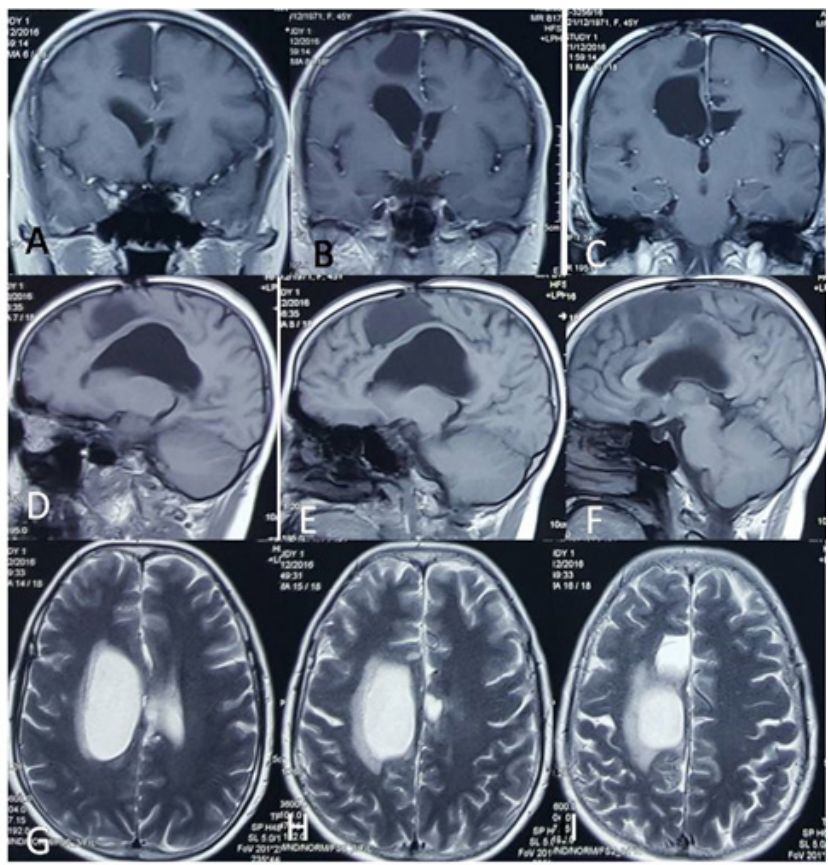

Figure 11. Postoperative MRI of brain

A, B, and C: Contrast coronal; D, E, and F: T1W sagittal; G, H, and I: T2W axial images showing much reduction in size of IAC with no mass effect. 
tive mortality or major morbidity related to surgery. One patient experienced symptoms of increased intracranial pressure 7 years after operation due to obliteration of third ventriculostomy and responded well after repeating ETV (Figure 4). One patient with concurrent cirrhosis of liver became symptoms free (due to IAC) postoperatively but died of liver failure 4 year after operation. Rest of the patients were doing well till last follow up.

\section{Discussion}

IACs are developmental abnormalities of the arachnoid membrane that gets duplicated or split. This occurs during the early embryonic period $[2,9,10]$. Arachnoid cysts are also associated with other central nervous system anomalies such as partial or complete agenesis of lobes [11]. CSF dynamics can result in an increase in the size of some cysts or rupture leading to elevated Intracranial Pressure (ICP). The underlying mechanisms may be active secretions from the cyst wall, a valve like mechanism, or obstructed outflow. Others include aberrant fluid dynamics and osmotic changes along the cyst wall $[2,9,12]$. This may cause a persistent and continual mass pressure that can affect the normal development and function of the surrounding brain [13-16]. The prevalence of IAC is $2.6 \%$ in children and $1.4 \%$ in adults $[6,7]$ and is a frequent incidental finding $[6,17]$.

IAC can be supratentorial or infratentorial. In supratentorial region, IAC can be in sylvian fissure, cerebral convexity, sellar or suprasellar, interhemispheric or quadrigeminal. In infratentorial region, IAC can be found in posterior midline, clival, cerebellopontine angle, vermis or in cistern magna [18]. Site distribution of IACs of our series was similar but we did not find any clival arachnoid cyst. Majority of IACs are asymptomatic [18]. However, IAC can present with symptoms depending on the location of cyst and age of the patient. Patients can present with headache, seizures, gait disturbances, cognitive decline, focal neurologic deficits, cranial nerve palsy, dimness of vision, and increase in head circumference [8]. Young patients are prone to cyst enlargement so they need surgical interventions as early as possible [6]. Suprasellar cysts usually present with typical bobble-head doll syndrome and endocrine or visual abnormalities.

Hydrocephalus is a common manifestation in posterior fossa cysts and periventricular cysts. In neonates and younger children, presenting symptoms are usually due to elevated ICP [3]. Neurosurgeons agree that symptomatic IACs patients who present with symptoms of intracranial hypertension, intractable seizures, and focal neurologic deficits warrant surgical management [1922]. Clinical features of IAC in our study were (in order of frequency) headache, hydrocephalus, gait disturbance, head asymmetry, visual disturbance, epilepsy and limb weakness. However, the most effective surgical management still remains controversial [23, 24]. Surgical options available are simple burr hole and cyst aspiration, open craniotomy for cyst removal or fenestration into adjacent arachnoid spaces, shunting or stenting of cyst contents into ventricle, endoscopic fenestration or cysto-peritoneal shunt operation [25]. Age is not a limiting factor for these surgical options [26].

Endoscopic decompression of the cyst is minimally invasive, safe, and easy, less time-consuming, and a lower incidence of postoperative complications. Other endoscopic procedures include endoscopic cysto-cisternostomy, cysto-ventriculostomy, or partial cyst wall excision [3]. The choice of surgery depends on the patient's age, the distance between the lesion and the neighboring ventricle or cistern, presence of hydrocephalus, mass effect caused by cyst, and relation with surrounding structures. Among surgical options, primary endoscopic fenestration appears to be an ideal procedure [27]. We used only endoscopic cysto-ventriculostomy and cystocisternostomy (where nearby ventricle was not available but cistern was available). Double fenestration was used in third/suprasellar arachnoid cysts. Where there was a thick layer of parenchyma between cyst and ventricle microsurgical assisted endoscopic cysto-ventriculostomy (rigid endoscope+ microsurgical instruments) was done and in such cases neuronavigation can be helpful for safety and accuracy.

Microsurgical craniotomy is some time preferred for patients with arachnoid cysts located in the cerebral convexity and intracerebral area. Local skull cranioplasty can be done in patients whose preoperative diagnosis showed features of cystic tumor or cyst-related epilepsy. Total resection or partial resection of the cyst wall can be for full fenestration. The combined use of microsurgical fenestration and cysto-ventriculostomy or cysto-cisternostomy can be performed simultaneously. Microsurgical craniotomy provides a full space for the total resection of the arachnoid cyst with Electrocorticography (ECoG) monitoring to record epileptic form discharges and thus localizing epileptogenic zone [28]. This approach also allows the surgeon to perform other procedures like focus excision, cortical thermo-coagulation, or local skull cranioplasty. Microsurgical craniotomy was more invasive than endoscopy, but it is argued that the microsurgical technique can obtain greater control of hemostasis because of the ability to use bipolar 
forceps [19]. A full space ensures the ability to perform another operation for cyst-related diseases, particularly in cyst-related epilepsy.

Extensive and mature application of endoscopy can replace microsurgical craniotomy gradually; however, the latter technique is more efficient for cortical arachnoid cysts, cyst-related epilepsy, or cysts with preoperative diagnosis for the possibility of a cystic tumor [23, 28]. Endoscopy is now a popular method for surgical treatment of arachnoid cysts. This treatment involves the use of a high-definition and stereo-vision system to visualize the arachnoid cyst and its neighboring structures. In addition, the technique provides an easy and minimally invasive method for cysto-ventriculostomy or cysto-cisternostomy. Therefore, endoscopy is a safe and effective therapeutic modality for IAC [29-31].

Cystoperitoneal shunting is effective for large cysts, particularly by using the low pressure shunt. However, recurrence of the cyst and shunt-related complications are the problems, thus cystoperitoneal shunting should not be the first choice nowadays. Surgical treatment of arachnoid cysts may occasionally result in complications, including pseudomeningocele and CSF leak [31] wound related complications [31, 33] infection, 31 subdural hygroma. [31, 33] subdural hematoma [32, 33] seizure [31] redo surgery [31, 32] and the risk of shunt dependency and its over drainage [34]. In patients with symptomatic arachnoid cysts, treatment may lead to lasting relief of focal neurological deficits $[35,36]$.

Seizures and headaches, however, often persist despite adequate surgical treatment of the cyst [31]. Most arachnoid cysts do not resolve completely as seen in our case series. In this series, postoperative imaging showed a significant decrease in cyst size in 7 patients and only a slight decrease in cyst size with a resolution of symptoms in others. Preoperative symptoms and signs were improved postoperatively like other endoscopic series in the literature. There was no mortality or major complication in our study that concur results of other reported endoscopic series in the literature [29-31].

The reason for noncollapsibility of these cysts is that they are developmental cysts and associated with agenesis of lobes $[2,9,12]$. Haemorrhage into the subdural space or into the arachnoid cyst has been reported in patients with arachnoid cysts [37-39]. It is a rare event and not even a single patient in the natural history group experienced a hemorrhage. Hemorrhages associated with arachnoid cysts that have been reported in the literature are generally related to good outcomes
[39] and surgery may not eliminate the risk of future hemorrhage in these patients $[18,40]$. Thus, prophylactic surgery is not recommended in asymptomatic IAC.

Our study had some limitations. Follow up period was too short to see the recurrence of IAC. As the number of operated cases are small, adult and pediatric patients are presented simultaneously. Therefore, one can argue that an arachnoid cyst in a pediatric patient is highly differentiated from a symptomatic arachnoid cyst in an adult although they may radiographically and histologically look similar. Finally, rigid and flexible endoscopic procedures and endoscopic microsurgical (rigid endoscope + microsurgical instruments) procedures are presented without differentiation.

\section{Conclusion}

In symptomatic IAC, endoscopic procedures (in different forms) are attractive surgical options. Almost all types of symptomatic IAC can safely and effectively be managed by endoscopic procedures. Thus, large craniotomy or various shunt procedures in IAC can effectively and efficiently be avoided.

\section{Ethical Considerations}

\section{Compliance with ethical guidelines}

There is no ethical principle to be considered doing this research.

\section{Funding}

This research did not receive any specific grant from funding agencies in the public, commercial, or not-forprofit sectors.

\section{Authors contributions}

All authors have read and approved the manuscript.

Conflict of interest

The authors declare no conflict of interest.

\section{References}

[1] Epelman M, Daneman A, Blaser SI, Ortiz-Neira C, Konen O, Jarrín $\mathrm{J}$, et al. Differential diagnosis of intracranial cystic lesions at head 
US: Correlation with CT and MR imaging. Radiographics. 2006 26(1):173-96 [DOI:10.1148/rg.261055033] [PMID]

[2] Rengachary SS. Intracranial arachnoid and ependymal cysts. In: Wilkins RH, Rengachary SS, editors. Neurosurgery. New York: McGraw-Hill; 1985.

[3] Raju S, Sharma RS, Moningi S, Momin J. Neuroendoscopy for intracranial arachnoid cysts in infants: Therapeutic considerations. Journal of Neurological Surgery 2016; 77(04): 333-43. [PMID]

[4] Wang C, Han G, You C, Liu C, Wang J, Xiong Y. Individual surgical treatment of intracranial arachnoid cyst in pediatric patients. Neurology India. 2013; 61(4):400-5. [DOI:10.4103/0028-3886.117618] [PMID]

[5] Rappaport ZH. Suprasellar arachnoid cysts: Options in operative management. Acta Neurochirurgica. 1993; 122(1-2):71-5 [DOI:10.1007/BF01446989]

[6] Al Holou WN, Yew AY, Boomsaad ZE, Garton HJ, Muraszko KM, Maher CO. Prevalence and natural history of arachnoid cysts in children. Journal of Neurosurgery: Pediatrics. 2010; 5(6):578-85 [DOI:10.3171/2010.2.PEDS09464]

[7] Al-Holou WN, Terman S, Kilburg C, Garton HJ, Muraszko KM, Maher CO. Prevalence and natural history of arachnoid cysts in adults. Journal of Neurosurgery. 2013; 118(2):222-31. [DOI:10.3171/2012.10. JNS12548] [PMID]

[8] Sharma M, Mittal RS, Bansal R, Sharma A. Intracranial arachnoid cyst: An institutional experience. Romanian Neurosurgery. 2016 30(1):136-42.

[9] Rengachary SS, Kennedy JD. Intracranial arachnoid cysts and ependymal cysts. In: Wilkins RH, Rengachary SS, editors. Neurosurgery. New York: McGraw-Hill; 1996.

[10] Nicholas M, Marion L. Arachnoid cysts. In: Winn HR, editor. You mans Neurological Surgery. Philadelphia: Saunders; 2011.

[11] Diakoumakis EE, Weinberg B, Mollin J. Prenatal sonographic diagnosis of a suprasellar arachnoid cyst. Journal of Ultrasound in Medicine. 1986; 5(9):529-30. [DOI:10.7863/jum.1986.5.9.529] [PMID]

[12] Oberbauer RW, Haase J, Pucher R. Arachnoid cysts in children: A European co-operative study. Child's Nervous System. 1992; 8(5):281-86. [DOI:10.1007/BF00300797] [PMID]

[13] Caemaert J, Abdullah J, Calliauw L, Carton D, Dhooge C, van Coster R. Endoscopic treatment of suprasellar arachnoid cysts. Acta Neurochirurgica. 1992; 119(1-4):68-73. [DOI:10.1007/BF01541784]

[14] Galassi E, Piazza G, Gaist G, Frank F. Arachnoid cysts of the middle cranial fossa: A clinical and radiological study of 25 cases treated surgically. Surgical Neurology. 1980; 14(3):211-19. [PMID]

[15] Raffel C, McComb JG. To shunt or to fenestrate: Which is the best surgical treatment for arachnoid cysts in pediatric patients? Neurosurgery. 1988; 23(3):338-42. [DOI:10.1227/00006123-19880900000009] [PMID]

[16] Schroeder HW, Gaab MR. Endoscopic observation of a slit-valve mechanism in a suprasellarprepontine arachnoid cyst: Case report. Neurosurgery. 1997; 40(1):198-200. [DOI:10.1097/00006123 199701000-00045] [PMID]

[17] Duz B, Kaya S, Daneyemez M. Surgical management strategies of intracranial arachnoid cysts: A single institution experience of 75 cases. Turkish Neurosurgery. 2012; 22(5):591-8. [DOI:10.5137/10195149.JTN.5616-11.0]
[18] Lee JY, Kim JW, Phi JH, Kim SK, Cho BK, Wang KC. Enlarging arachnoid cyst: A false alarm in infants. Child's Nervous System. 28(8):1203-11. [DOI: 10.1007/s00381-012-1722-z] [PMID]

[19] Hellwig D, Schulte M, Tirakotai W. Surgical management of arachnoid, suprasellar, and Rathke's cleft cysts. In: Schmidek HH, Roberts DW, editors. Schmidek and Sweet Operative Neurosurgical Techniques. Vol 1. Philadelphia: Saunders; 2006

[20] Gelabert-González M, Serramito-García R, García-Allut A. [Spontaneous resolution of an asymptomatic intracranial arachnoid cysts (Spanish)]. Neurocirugia. 2008; 19(4):361-4. [PMID]

[21] Gangemi M, Colella G, Magro F. Suprasellar arachnoid cysts: Endoscopy versus microsurgical cyst excision and shunting. British Journal of Neurosurgery. 2007; 21(3):276-80. [DOI:10.1080/02688690701339197] [PMID]

[22] Gangemi M, Seneca V, Colella G, Cioffi V, Imperato A, Maiuri F. Endoscopy versus microsurgical cysts excision and shunting for treating intracranial arachnoid cysts. Journal of Neurosurgery: Pediatrics. 2011; 8(2):158-64. [DOI:10.3171/2011.5.PEDS1152]

[23] Gallentine WB, Mikati MA. Intraoperative electrocorticography and cortical stimulation in children. Journal of Clinical Neurophysiology. 2009; 26(2):95-108. [DOI:10.1097/WNP.0b013e3181a0339d] [PMID]

[24] Gui SB, Wang XS, Zong XY, Li CZ, Li B, Zhang YZ. Assessment of endoscopic treatment for middle cranial fossa arachnoid cysts. Child's Nervous System. 2011; 27(7):1121-28. [DOI:10.1007/s00381-011 1399-8] [PMID]

[25] Oertel JM, Wagner W, Mondorf Y, Baldauf J, Schroeder HW, Gaab MR. Endoscopic treatment of arachnoid cysts: A detailed account of surgical techniques and results. Neurosurgery. 2010; 67(3):824-36 [DOI:10.1227/01.NEU.0000377852.75544.E4] [PMID]

[26] Yadav YR, Parihar V, Sinha M, Jain N. Endoscopic treatment of the suprasellar arachnoid cyst. Neurology India. 2010; 58(2):280-83. [DOI:10.4103/0028-3886.63772] [PMID]

[27] Kandasamy J, Souweidane M. Editorial: Arachnoid cysts. Journal of Neurosurgery: Pediatrics. 2012; 9(3):22830 [DOI:10.3171/2011.11. PEDS11411] [PMID]

[28] Helland CA, Wester K. A population-based study of intracranial arachnoid cysts: Clinical and neuroimaging outcomes following surgical cyst decompression in children. Journal of Neurosurgery. 2006; 105(5 Suppl):385-90. [PMID]

[29] Koch CA, Moore JL, Voth D. Arachnoid cysts: How do postsurgical cyst size and seizure outcome correlate? Neurosurgical Reviews. 1998; 21(1):14-22. [DOI:10.1007/BF01111480] [PMID]

[30] Karabagli H, Etus V. Success of pure neuroendoscopic technique in the treatment of Sylvian arachnoid cysts in children. Child's Nervous System. 2012; 28(3):445-52. [DOI:10.1007/s00381-011-1632-5] [PMID]

[31] Levy ML, Wang M, Aryan HE, Yoo K, Meltzer H. Microsurgical keyhole approach for middle fossa arachnoid cyst fenestration. Neurosurgery. 2003; 53(5):1138-44. [DOI:10.1227/01. NEU.0000089060.65702.03] [PMID]

[32] Kang JK, Lee KS, Lee IW, Jeun SS, Son BC, Jung CK, et al. Shuntindependent surgical treatment of middle cranial fossa arachnoid cysts in children. Child's Nervous System. 2000; 16(2):111-6. [DOI:10.1007/s003810050024] [PMID] 
[33] Marin-Sanabria EA, Yamamoto H, Nagashima T, Kohmura E. Evaluation of the management of arachnoid cyst of the posterior fossa in pediatric population: Experience over 27 years. Child's Nervous System. 2007; 23(5):535-42. [DOI:10.1007/s00381-006-0284-3] [PMID]

[34] Martínez-Lage JF, Ruíz-Espejo AM, Almagro MJ, Alfaro R, FelipeMurcia M, López-Guerrero AL. CSF overdrainage in shunted intracranial arachnoid cysts: A series and review. Child's Nervous System. 2009; 25(9):1061-9. [DOI:10.1007/s00381-009-0910-y] [PMID]

[35] Boutarbouch M, El Ouahabi A, Rifi L, Arkha Y, Derraz S, El Khamlichi A. Management of intracranial arachnoid cysts: Institutional experience with initial 32 cases and review of the literature. Clinical Neurology and Neurosurgery. 2008; 110(1):1-7. [DOI:10.1016/j. clineuro.2007.08.009] [PMID]

[36] Shim KW, Lee YH, Park EK, Park YS, Choi JU, Kim DS. Treatment option for arachnoid cysts. Child's Nervous System. 2009; 25(11):1459-66. [DOI:10.1007/s00381-009-0930-7] [PMID]

[37] Bilginer B, Onal MB, Oguz KK, Akalan N. Arachnoidcyst associated with subdural hematoma: Report of three cases and review of the literature. Child's Nervous System. 2009; 25:119-24. [DOI:10.1007/ s00381-008-0728-z] [PMID]

[38] Domenicucci M, Russo N, Giugni E, Pierallini A. Relationship be tween supratentorial arachnoid cyst and chronic subdural hematoma: Neuroradiological evidence and surgical treatment. Journal of Neurosurgery. 2009; 110(6):1250-55. [DOI:10.3171/2008.4.17509] [PMID]

[39] Parsch CS, Krauss J, Hofmann E, Meixensberger J, Roosen K. Arachnoid cysts associated with subdural hematomas and hygromas: Analysis of 16 cases, long-term follow-up, and review of the literature. Neurosurgery. 1997; 40(3):483-90. [DOI:10.1227/00006123199703000-00010]

[40] Spacca B, Kandasamy J, Mallucci CL, Genitori L. Endoscopic treatment of middle fossa arachnoid cysts: A series of 40 patients treated endoscopically in two centres. Child's Nervous System. 2010; 26(2):163-72. [DOI:10.1007/s00381-009-0952-1] [PMID] 
This Page Intentionally Left Blank 